standardization. The Division of Electrotechnology, too, made considerable progress in establishing further electrical standards and extending the scope of its measuring facilities.

The Division of Physics continued its policy of increasing the amount of fundamental research as compared with short-term technical investigations, progress being recorded on the studies of the formation of rain, on the solar atmosphere and other phenomena; but staff shortage was a severe handicap. The Heat and Light Sections concentrated their attention on the phenomena of ice crystal formation and the attainment of very low temperatures, and on photometry respectively. Aeronautical investigations under the new Aeronautical Research Committee dealt with aircraft structures, properties of alloys, gas-turbines and high-speed flow. In the Division of Industrial Chemistry, pilot tests of a new process for the production of chromic anhydride from chrome iron ore by an acid digestion method were completed, and work on monazite, rutile, zircon and uranium ores continued, as well as on the deterioration of concrete. Among many other investigations may be cited those on Australian substitutes for linseed oil, the use of long-chain carbon compounds in the differential flotation process and detergents in wool scouring. In radiophysics the chief features of the year were work on radio-frequency emissions from the sun, cosmic noise, the ionosphere and the use of radar for surveying and navigation.

The Division of Tribophysics studied the nature of the forces restraining the movement of clean metal surfaces over each other, and the physical and chemical properties of the films of molecular dimensions used as boundary lubricants. Other departments which recorded satisfactory progress during the year are the Building Materials Research Section, the Dairy Products Research Board, and the Section of Mathematical Statistics. The report also refers briefly to research work in the Atomic Physics Section, and on the growth and rubber content of the guayule plant under Australian conditions.

\section{VOYAGE OF THE ROYAL RESEARCH SHIP DISCOVERY II}

$\mathrm{T}$

THE Royal Research Ship Discovery II, at present in the West India Dock, Port of London, is to sail shortly on a voyage of deep-sea research, mainly in the Southern Ocean and Antarctic. This follows the departure in January of the Royal Research Ship William Scoresby on a tonmonth voyage for investigations on oceanography and whales in South African and Australian waters (see Nature, January 21, p. 105). The two ships have, independent programmes; but their work for the present is principally in continuation of the Discovery Investigations, formerly under the Colonial Office and now transferred to the Admiralty as a part of the National Institute of Oceanography.

The main purpose of the voyage of the Discovery $I I$ is to round off a general oceanographical survey of the Southern Ocean which had been nearly completed by the former Discovery Committee before the Second World War. This survey is important for two reasons : first, it gives the necessary background to investigations on whales and other oceanic life in the far south with which the Committeo was specially concerned, and secondly, it is itself an important step forward in the exploration of the oceans and will give opportunities for carrying out many special investigations of basic importance to the science of oceanography.

There is a relative simplicity in the water circulation and distribution of life in the Southern Ocean, so that generalizations can often be made from fewer observations than in other regions, and principles can be established which apply to all oceans. The voyage is to last about a year and a half, and the ship will work mainly in the Indian, Australian and Pacific sectors of the Southern Ocean between subtropical waters and the fringe of the pack ice. The work, however, will not be confined to these regions, for on the outward voyage a line of deep-sea observations will be made in the little-known central Indian Ocean. The scientific work of the voyage will begin in earnest when the ship leaves Colombo and steams southward on the meridian of $90^{\circ} \mathrm{E}$. At regular intervals the ship will be stopped on station, and temperature, density and chemical constituents of the water will be ascertained from the surface to the bottom, and the plankton from the surface to a depth of about 1,500 metres. The ship will call at Fremantle in July and then complete the same line of stations in the Indian Ocean, southwards to the pack ice. Thereafter she will work eastwards, carrying out similar work between ports in Australia and New Zealand and the Antarctic. These lines of deep-sea stations form the essence of the whole programme. Taken with the work done before the War, they will provide a network of observations covering the whole Southern Ocean, from which the main water-masses and currents and the various forms of oceanic life can be mapped out not only horizontally but also in vertical sections.

Many subjects will receive special attention during and between the principal lines of stations. Echo soundings will be taken wherever the ship goes, sometimes with the continuous recorder; deep cores of the sea bottom will be taken from time to time by the method used in the recent Swedish expedition in the Albatross, and some measurements of the depths of ocean sediments will be made with the seismic sounding-apparatus developed in recent years. Direct observations will be made on the distribution and habits of whales, and on seals, fish and birds according to opportunities. The 'convergences'-certain surface boundaries between important water masseswill receive attention, the seasonal distribution of pack ice will be studied, and there may at a later stage be opportunities to examine and chart a littleknown part of the Antarctic coast.

Other work includes soundings and amendments to charts for the Admiralty Hydrographic Department, routine observations for the Meteorological Office and physiological work for the Royal Naval Personnel Research Committee.

The Discovery $I I$ is an oil-burning steamship of 1,036 tons (gross), specially designed as a research ship, and with some protection against ice. She was bujlt in 1929, but in recent months has undergone an extensive refit, and is now supplied with very comprehensive equipment for deep-sea research. Her total complement is about fifty-six officers and men, including four scientific officers and three assistants. Dr. H. F. P. Herdman is the senior scientific worker in charge of the work at sea, and Commander J. F. Blackburn is in executive command. Dr. N. A. Mackintosh, director of the Discovery Investigations, will sail with the ship for the first part of the voyage. 